\title{
Grey Correlation Analysis of Decathlon Achievement of the World Elite Athletes Ashton James Eaton
}

\author{
Changmei Huang \\ Institute of Physical Education \\ Hunan University of Science and Technology \\ Xiangtan Hunan, P.R. China \\ changmeihuang@126.com
}

\author{
Yang He \\ Institute of Physical Education \\ Hunan University of Science and Technology \\ Xiangtan Hunan, P.R. China \\ Heyangmail@163.com
}

\begin{abstract}
Using the methods of mathematical statistics and correlation analysis and grey correlation analysis, the paper studied on multi-level grey correlation analysis of Olympic champion Ashton James Eaton achievement. The results reveal the relationship of total result and event-groups, event-group and individual event, individual events. Skip event-group and speed event-group are his advantage project, and endurance event-group is his weaker project. The order of affecting total score of Ashton James Eaton is $100 \mathrm{~m}$, high jump, $110 \mathrm{~m}$ hurdles, $400 \mathrm{~m}$, javelin, shot put, long jump, discus, $1500 \mathrm{~m}$ and pole vault. In the end, the paper divided ten events into four classes, and analyzed Ashton James Eaton's advantage and disadvantage events.
\end{abstract}

Keywords- Decathlon; Ashton James Eaton Sports Achievement; Grey Correlation Analysis

\section{INTRODUCTION}

Grey system theory was pioneered by Deng Julong in 1982, which focuses on "the partial information is known, and the partial information is unknown" uncertainty system[1,2]. Grey correlation analysis of the grey system theory is a quantization process which studies the close degree of each factor against the main factors, and that is the comparison of the quantitative and analysis of relevant factors (sub-factors and main factors). It is a powerful algorithm tool which can solve the question in which partial information is vague and unclear. Olympic track and field event includes many events $(100 \mathrm{~m}, 400 \mathrm{~m}, 110 \mathrm{~m}$ hurdle, long jump, shot put, high jump, pole vault, discus, javelin,1500 meters), and decathlon achievement is influenced by those factors, such as athletes individual growth cycle, the physical quality, the outstanding performance of athletes and injuring, etc. Those factors can make the match result uncertain, and the decathlon achievement has obviously grey features, and so, we can view decathlon achievement system as a grey system. In this paper, we collected decathlon athletes Ashton Eaton James' total achievements in latest three years in largescale sport events to study the influence degree of each group between the total score and each individual event in order to reveal dependencies relation between events, and analyzed Ashton James Eaton's advantage and disadvantage events in order to improve selecting of the world elite male decathlon and making training plan with beneficial reference.

\section{RESEARCH OBJECTS AND METHODS}

\section{A. Research Objects}

Ashton Eaton James was born in Portland, Oregon, on January 21, 1988 and is an American decathlete, holding the world record in both the decathlon and heptathlon events, and also is only the second decathlete (after Roman Šebrle) to break the 9,000-point barrier, with 9,039 points. Ashton Eaton James won The Bowerman award in 2010. In the next year 2011, he won the first international medal of his career, a silver, in the decathlon at the 2011 World Championships. And in the 2012 World Indoor Championships, he broke his own world record in the heptathlon, and then went on to break the world record in the decathlon at the Olympic Trials. After setting the world record, Eaton won the gold medal at the 2012 Summer Olympics in London. We collected decathlon athletes Ashton Eaton James' total achievements in latest three years in large-scale sport events, which shown in table I, and the detail achievements are omitted.

TABLE I. ACHIEVEMENTS OF ASHTON JAMES EATON IN LATEST THREE YEARS

\begin{tabular}{|c|c|c|c|}
\hline $\begin{array}{c}\text { Competition } \\
\text { Time }\end{array}$ & $\begin{array}{c}\text { Competition } \\
\text { Results }\end{array}$ & $\begin{array}{c}\text { Competition } \\
\text { Ranking }\end{array}$ & $\begin{array}{c}\text { Competition } \\
\text { Site }\end{array}$ \\
\hline 2010.4 .1 & 8310 & 1 & Austin 2010 \\
\hline 2010.5 .9 & 8154 & 1 & Berkeley 2010 \\
\hline 2010.6 .11 & 8457 & 1 & Eugene 2010 \\
\hline 2011.6 .24 & 8729 & 1 & Eugene 2011 \\
\hline 2011.8 .28 & 8505 & 2 & Daegu 2011 \\
\hline 2012.6 .23 & 9039 & 1 & Eugene 2012 \\
\hline 2012.8 .9 & 8869 & 1 & London 2012 \\
\hline
\end{tabular}

\section{B. Research Methods}

The paper collects 50 research papers of recent domestic and foreign literatures related to men's decathlon sports, and collects Ashton Eaton James' achievements in latest three years in large-scale sport events. Then, we use mathematical statistics, statistical software to process data. At last, we use grey relation analysis method, which is an important part of grey system theory, to compute the grey correlation degree, correlation sequence, weight and weight sequence of the Ashton Eaton James' achievements 
in multiple perspectives and multi-level grey correlation analysis.

\section{PROCESS OF GREY CORRELATION ANALYSIS}

Procedure of grey relational analysis is treated as follow:

(1) Determine the factors listed

Mother factor $\mathrm{w}_{0}$ (total result), which is evaluated as follows:

$w_{0}=\left[w_{0}(k)\right], k \in\{1, \cdots, \mathrm{n}\}$, where $\mathrm{n}$ is the number of cases;

Sub-factors $\mathrm{w}_{1}, \mathrm{w}_{2}, \mathrm{w}_{3}, \mathrm{w}_{4}, \mathrm{w}_{5}, \mathrm{w}_{6}, \mathrm{w}_{7}, \mathrm{w}_{8}, \mathrm{w}_{9}, \mathrm{w}_{10}$ (individual results or event-groups), which are evaluated as follow:

$w_{i}=\left[w_{i}(k)\right], i \in\{1, \cdots, \mathrm{m}\}, k \in\{1, \cdots, \mathrm{m}\}$, where $\mathrm{m}$ is number of individual or event-group.

(2) Determine the spaces of factors @GRF.

@GRF is evaluated as follow:

$$
\begin{gathered}
x_{i}=A V G w_{i}, A V G: x_{i}(k)=\frac{w_{i}(k)}{w_{i}(a v g)} \\
w_{i}(a v g)=\frac{1}{n} \sum_{k=1}^{\mathrm{n}} w_{i}(k), i \in\{0, \cdots, \mathrm{m}\} .
\end{gathered}
$$

(3) Determine $\triangle \mathrm{GR}$

The smallest difference and the polarization the polarization maximum differential, which is evaluated as follows:

$\Delta_{0 i}(k)=\left|x_{0}(k)-x_{i}(k)\right|, i \in\{1, \cdots, \mathrm{m}\}, k \in\{1, \cdots, \mathrm{m}\}$,

(4) Seek correlation (first order correlation coefficient then order correlation)

By $\triangle_{\mathrm{GR}}$, we can get $\triangle_{0 \mathrm{i}}(\max )$ and $\triangle_{0 \mathrm{i}}$ (min), make the identification coefficient, $\xi=0.5$, and grey correlation coefficient

$$
\begin{gathered}
\left.\Delta_{0 i}(k)=\left|x_{0}(k)-x_{i}(k)\right|\right\} \\
i \in\{1, \cdots, \mathrm{m}\}, k \in\{1, \cdots, \mathrm{n}\}, \\
r\left(x_{0}(k), x_{i}(k)\right)=\frac{\Delta_{0 i}(\min )+\xi \Delta_{0 i}(\max )}{\Delta_{0 i}(k)+\xi \Delta_{0 i}(\max )} .
\end{gathered}
$$

(5) Seek grey relational grade, sequence, and weight $r\left(x_{0}, x_{k}\right)=\frac{1}{n} \sum_{k=1}^{n} r\left(x_{0}(k), x_{i}(k)\right), w_{i}=r_{i} / \sum r_{k}$.

\section{RESULTS AND DISCUSSION}

\section{A. Grey Correlation Analysis of Total Result against} Event-groups of Ashton Jame Eaton's Achievement

Ten events can be divided into four classes, which are speed event-group $(100 \mathrm{~m}, 400 \mathrm{~m}, 110 \mathrm{~m}$ hurdles), skip event-group(high jump, long jump and pole vault), throwing event-group(shot put, discus, javelin) and endurance event-group(1500m). According to grey correlation analysis formula, we can get the results shown in table I.

From table II, The grey correlation sequence (GCS) of four event-groups against total Ashton James Eaton is skip event-group $>$ speed event-group $>$ endurance eventgroup $>$ throwing event-group, and their weight sequence is the same as the grey correlation sequence.

TABLE II. GREY CORRELATION DEGREE, CORRELATION SEQUENCE, WEIGHT AND WEIGHT SEQUENCE OF TOTAL AND EVENT-GROUPS

\begin{tabular}{|c|c|c|c|c|}
\hline $\begin{array}{c}\text { Indicators/ } \\
\text { Items }\end{array}$ & $\begin{array}{c}\text { Speed } \\
\text { Event-group }\end{array}$ & $\begin{array}{c}\text { Skip Event- } \\
\text { group }\end{array}$ & $\begin{array}{c}\text { Throwing } \\
\text { Event-group }\end{array}$ & $\begin{array}{c}\text { Endurance } \\
\text { Event-group }\end{array}$ \\
\hline GCD & 0.8929 & 0.9028 & 0.7054 & 0.7150 \\
\hline GCS & 2 & 1 & 4 & 3 \\
\hline GCW(\%) & $27.76 \%$ & $28.07 \%$ & $21.93 \%$ & $22.23 \%$ \\
\hline
\end{tabular}

From the GCD and GCW, the biggest contribution to total score is skip event-group with the contribution rate of $28.07 \%$, followed by the speed event-group with the contribution rate of $27.76 \%$, then by endurance eventgroup with the contribution rate of $22.237 \%$, and the smallest contribution is throwing event-group, accounted for $21.93 \%$. All those show that skip event-group and endurance event-group have the bigger influence on the total score and with higher training level, skip event-group is leading the development of the project and while throwing event-group is relatively weak.

\section{B. Grey Correlation Analysis of Event-groups of Ashton Jame Eaton's Achievement}

TABLE III. GREY CORRELATION DEGREE, RELATIONAL SEQUENCE AND WEIGHT OF SPEED AND OTHER EVENT-GROUPS

\begin{tabular}{|c|c|c|c|}
\hline $\begin{array}{c}\text { Indicators/ } \\
\text { Items }\end{array}$ & $\begin{array}{c}\text { Skip Event- } \\
\text { group }\end{array}$ & $\begin{array}{c}\text { Throwing Event- } \\
\text { group }\end{array}$ & $\begin{array}{c}\text { Endurance Event- } \\
\text { group }\end{array}$ \\
\hline GCD & 0.8118 & 0.6872 & 0.6814 \\
\hline GCS & 1 & 2 & 3 \\
\hline GCW(\%) & $37.23 \%$ & $31.52 \%$ & $31.25 \%$ \\
\hline
\end{tabular}

TABLE IV. GREY CORRELATION DEGREE, CORRELATION SEQUENCE, WEIGHT AND WEIGHT SEQUENCE OF SKIP AND OTHER EVENT-GROUPS

\begin{tabular}{|c|c|c|c|}
\hline $\begin{array}{c}\text { Indicators/ } \\
\text { Items }\end{array}$ & $\begin{array}{c}\text { Speed Event- } \\
\text { group }\end{array}$ & $\begin{array}{c}\text { Throwing Event- } \\
\text { group }\end{array}$ & $\begin{array}{c}\text { Endurance Event- } \\
\text { group }\end{array}$ \\
\hline GCD & 0.8238 & 0.6273 & 0.6952 \\
\hline GCS & 1 & 2 & 3 \\
\hline GCW(\%) & $38.38 \%$ & $29.23 \%$ & $32.39 \%$ \\
\hline
\end{tabular}

TABLE V. GREY CORRELATION DEGREE, CORRELATION SEQUENCE, WEIGHT AND WEIGHT SEQUENCE OF THROWING AND OTHER EVENTGROUPS

\begin{tabular}{|c|c|c|c|}
\hline $\begin{array}{c}\text { Indicators/ } \\
\text { Items }\end{array}$ & $\begin{array}{c}\text { Speed Event- } \\
\text { group }\end{array}$ & $\begin{array}{c}\text { Skip Event- } \\
\text { group }\end{array}$ & $\begin{array}{c}\text { Endurance Event- } \\
\text { group }\end{array}$ \\
\hline GCD & 0.7873 & 0.7192 & 0.6933 \\
\hline GCS & 1 & 2 & 3 \\
\hline GCW(\%) & $35.79 \%$ & $32.70 \%$ & $31.52 \%$ \\
\hline
\end{tabular}

TABLE VI. GREY CORRELATION DEGREE, CORRELATION SEQUENCE, WEIGHT AND WEIGHT SEQUENCE OF ENDURANCE AND OTHER EVENTGROUP

\begin{tabular}{|c|c|c|c|}
\hline $\begin{array}{c}\text { Indicators/ } \\
\text { Items }\end{array}$ & $\begin{array}{c}\text { Speed Event- } \\
\text { group }\end{array}$ & $\begin{array}{c}\text { Skip Event- } \\
\text { group }\end{array}$ & $\begin{array}{c}\text { Throwing Event- } \\
\text { group }\end{array}$ \\
\hline GCD & 0.7886 & 0.7840 & 0.6924 \\
\hline GCS & 1 & 2 & 3 \\
\hline GCW(\%) & $34.82 \%$ & $34.61 \%$ & $30.57 \%$ \\
\hline
\end{tabular}


From table III to table VI, the grey correlation sequence (GCS) of speed event-group against other three event-groups is skip event-group>throwing eventgroup>endurance event-group. The grey correlation sequence of skip event-group against other three eventgroups is speed event-group>throwing eventgroup>endurance event-group. The grey correlation sequence of throwing event-group against other three event-groups is speed event-group>skip eventgroup>endurance event-group. The grey correlation sequence of endurance event-group against other three event-groups is speed event-group>skip event-group >skip event-group.

\section{Grey Correlation Analysis of Event-group against Individual Events of Ashton Jame Eaton's Achievement}

TABLE VII. GREY CORRELATION DEGREE, CORRELATION SEQUENCE, WEIGHT AND SEQUENCE OF SPEED EVENT-GROUP AND INDIVIDUAL EVENT

\begin{tabular}{|c|c|c|c|}
\hline Indicators/Items & $100 \mathrm{~m}$ & $400 \mathrm{~m}$ & $110 \mathrm{~m}$ hurdle \\
\hline GCD & 0.5886 & 0.6153 & 0.5889 \\
\hline GCS & 3 & 1 & 2 \\
\hline GCW(\%) & $32.83 \%$ & $34.32 \%$ & $32.85 \%$ \\
\hline
\end{tabular}

TABLE VIII. GREY CORRELATION DEGREE, CORRELATION SEQUENCE, WEIGHT AND SEQUENCE OF SKIP EVENT-GROUP AND INDIVIDUAL EVENT

\begin{tabular}{|c|c|c|c|}
\hline Indicators/Items & Long jump & High jump & pole vault \\
\hline GCD & 0.7476 & 0.6815 & 0.5946 \\
\hline GCS & 1 & 2 & 3 \\
\hline GCW(\%) & $36.94 \%$ & $33.68 \%$ & $29.38 \%$ \\
\hline
\end{tabular}

TABLE IX. GREY CORRELATION DEGREE, CORRELATION SEQUENCE, WEIGHT AND SEQUENCE OF THROWING EVENT-GROUP AND INDIVIDUAL EVENT

\begin{tabular}{|c|c|c|c|}
\hline Indicators/Items & Shot put & discus & javelins \\
\hline GCD & 0.7629 & 0.4870 & 0.5838 \\
\hline GCS & 1 & 3 & 2 \\
\hline GCW(\%) & $41.61 \%$ & $26.56 \%$ & $31.84 \%$ \\
\hline
\end{tabular}

From table VII to table VIX, the grey correlation sequence (GCS) of individual event against speed eventgroups is $400 \mathrm{~m}>110 \mathrm{~m}$ hurdles $>100 \mathrm{~m}$. From the GCD and weight, the biggest contribution to speed event-group is $400 \mathrm{~m}$ with the contribution rate of $34.32 \%$, followed by $110 \mathrm{~m}$ hurdles and $100 \mathrm{~m}$ with the contribution rate of $32.85 \%$, 32.83\%. The grey correlation sequence (GCS) of individual event against skip event-group is long jump>high jump>pole vault. From the GCD and weight, the biggest contribution to skip event-group is long jump with the contribution rate of $36.94 \%$, followed by high jump and pole vault with the contribution rate of 33.68\%, $29.38 \%$. The grey correlation sequence (GCS) of individual event against throwing event-group is shot put $>$ javelin $>$ discus. It shows that shot put is the bigger influence factor on the throwing event-group, and reveals the higher training level relatively, and followed by the javelin, while discus is relatively weak.

\section{Grey Correlation Analysis of Total Result against Individual Events of Ashton Jame Eaton's Achievement}

TABLE X. GREY CORRELATION DEGREE, CORRELATION SEQUENCE, WEIGHT AND WEIGHT SEQUENCE OF TOTAL RESULT AND INDIVIDUAL EVENT

\begin{tabular}{|c|c|c|c|c|c|}
\hline $\begin{array}{c}\text { Indicators } \\
\text { /Items }\end{array}$ & $100 \mathrm{~m}$ & $\begin{array}{c}\text { Long } \\
\text { jump }\end{array}$ & Shot put & $\begin{array}{c}\text { High } \\
\text { jump }\end{array}$ & $400 \mathrm{~m}$ \\
\hline GCD & 0.8113 & 0.6081 & 0.6384 & 0.7897 & 0.7338 \\
\hline GCS & 1 & 7 & 6 & 2 & 4 \\
\hline GCW(\%) & $12.44 \%$ & $9.32 \%$ & $9.78 \%$ & $12.10 \%$ & $11.25 \%$ \\
\hline $\begin{array}{c}\text { Indicators } \\
\text { /Items }\end{array}$ & $\begin{array}{c}110 \mathrm{~m} \\
\text { hurdle }\end{array}$ & discus & $\begin{array}{c}\text { pole } \\
\text { vault }\end{array}$ & javelins & $1500 \mathrm{~m}$ \\
\hline GCD & 0.7604 & 0.5600 & 0.4771 & 0.6390 & 0.5067 \\
\hline GCS & 3 & 8 & 10 & 5 & 9 \\
\hline GCW(\%) & $11.65 \%$ & $8.58 \%$ & $7.31 \%$ & $9.79 \%$ & $7.77 \%$ \\
\hline
\end{tabular}

From table $\mathrm{X}$, the order of affecting total score of Ashton James Eaton decathlon achievement is $100 \mathrm{~m}>$ high jump $>110 \mathrm{~m}$ hurdles $>400$ meters $>$ javelin $>$ shot put $>$ long jump $>$ discus $>1500 \mathrm{~m}>$ pole vault. Their weight sequence is the same as the grey relational sequence. From the grey relation of each single weight, it shows that the biggest contribution rate to total is the $100 \mathrm{~m}$, accounted for $12.44 \%$, followed by high jump, accounted for $12.10 \%$,and the smallest contribution rate is the pole vault, accounted for 7.31\%. According to GCD and GCW, the decisive factors are 100 meters, high jump, 110 meters hurdle and 400 meters, with GCW $12.44 \%, 12.10 \%$, $11.65 \%$ and $12.44 \%$ respectively. The important factors are the javelin, shot put, and jump, with GCW 9.79\%, $9.78 \%$ and $9.32 \%$, respectively. The less important factors are discus and 1500 meters, with GCW 8.58\% and 7.77\% respectively. The fundamental factor is pole vault, with GCW 7.31\%. The advantage project of Ashton James Eaton are 100 meters, high jump, 110 meters hurdles, 400 meters, javelin, shot put, long jump and discus , contributed more than 8.56, and the weaker project are 1500 meters and pole vault with contribution rate $7.30 \%$ and $7.78 \%$.

\section{CONCLUSION}

1. Based on the results of grey correlation degree and sequence of total against event-groups of decathlon athletes Olympic champion Ashton James Eaton achievement, Skip event-group and speed event-group are his advantage project; throwing event-group and endurance event-group are his weaker projects. All these show significantly different.

2. Based on the results of grey correlation degree and sequence between event-groups of decathlon athletes Olympic champion Ashton James Eaton achievement, skip, throwing, endurance event-groups are most closely related to speed event-group; the relationship of speed, skip, throwing against endurance is the weakest. Speed eventgroup is his winning magic weapon.

3. According to Ashton James Eaton's Advantages and disadvantages relations of each event-group with its individual, $400 \mathrm{~m}$ shows the biggest influence factor to the 
speed event-group, which reflects the $400 \mathrm{~m}$ training level is relatively high, followed by the $110 \mathrm{~m}$ hurdles, 100 meters is relatively weak. Long jump shows the biggest influencing factor to skip event-group, which reflects long jump training level is relatively high, the second is the high jump, and pole vault are relatively weak. Shot put shows the biggest influencing factor to throwing eventgroup, which reflects shot put training level is relatively high, the second is the javelin, and discus is relatively weak. All these illustrate his technical and rapid speed power, strength and skill have developed better.

4. From the grey correlation result of Ashton James Eaton's decathlon achievement of total against individual event, his advantage projects are 100 meters, high jump, 110 meters hurdles, 400 meters, javelin, shot put, long jump and discus. 1500 meters and pole vault are his weaker projects.

\section{ACKNOWLEDGMENT}

This work is supported by Hunan province teaching reform research project(G21209), Hunan province colleges and universities scientific research project(11C0545), and
Hunan province department of education project (11C0546).

\section{REFERENCES}

[1] Deng Julong. "Grey System Theory Base (3rd Edition)" . Hubei, China: huazhong university of science and technology press,2002,pp. 122-171.

[2] LIU Sifeng, Dang Yaoguo, FANG Zhijian ."Grey System Theory and Application(3rd Edition)”, Beijing, China: science press,2004,pp. 50-76.

[3] ZHENG Yi-le; JIA Chang-zhi. Gray Correlative Analysis of the Achievement of Top Chinese and Foreign Decathlon Athletes, Journal of Beijing University of Physical Education,2004,24(8): 1135-1136.

4] HUANG Chang-mei. Grey Relational Analysis on the Achievements and Physical Quality of the World Excellent Male Shot Putter, Journal of Physical Education Institute of Shanxi Normal University, 2009,24(1):92-95.

[5] Huang Changmei,Shen Weihua. Feature Analysis on Result of World Outstanding Men's Decathlon, Journal of Jilin Institute of Physical Education, 2010,26(5):65-66.

[6] Weihua Shen,Changmei Huang, Xiaocong Xiao.Grey Correlation in the Competing Results of the World Best Men's Decathletes,Proc.of The 21th Pan-Asian congress of Sports \& Physical 